\title{
Chemopreventive and Anticancer Effects of Thymoquinone: Cellular and Molecular Targets
}

\author{
Rohini Gomathinayagam', Ji Hee Ha', Muralidharan Jayaraman', Yong Sang Song ${ }^{2}$, Ciro Isidoro ${ }^{3}$, \\ Danny N. Dhanasekaran' \\ ${ }^{1}$ Stephenson Cancer Center, Department of Cell Biology, The University of Oklahoma Health Sciences Center, Oklahoma \\ City, OK, USA, ${ }^{2}$ Department of Obstetrics and Gynecology, Cancer Research Institute, College of Medicine, Seoul National \\ University, Seoul, Korea, ${ }^{3}$ Laboratory of Molecular Pathology and NanoBiolmaging, Department of Health Sciences, \\ Università del Piemonte Orientale, Novara, Italy
}

\begin{abstract}
Thymoquinone (TQ) is a bioactive component derived from the seeds of Nigella sativa that are commonly as black cumin. Evidences indicate that the medicinal properties of TQ have been recognized for more than 2000 years. TQ has been shown to possess potent chemopreventive properties that include anti-inflammatory and anti-neoplastic activities. Recent studies have unraveled the multiple mechanisms through which TQ exerts its chemopreventive and anticancer activity in different cancer cells in a contextual manner. The present review aims to provide a brief compendium on the molecular mechanisms through which TQ inhibits signaling pathways underlying cancer genesis, progression, and metastasis.
\end{abstract}

Key Words Nigella sativa, Thymoquinone, Neoplasms, Chemoprevention, Antineoplastic agent

\section{INTRODUCTION}

Carcinogenesis is a multistep process that involves the transformation of a normal cell to a malignant one. Clinically, the series of events from pre-malignancy to malignancy is progressively observed as dysplasia, hyperplasia, tumorigenic malignancy and metastasis. Recent studies have identified that both genetic and environmental factors play a critical role in cancer development and progression. It has also been realized that cancers could be prevented or at least cancer initiation and/or progression could be delayed by naturally-occurring, dietary compounds [1-4]. Most, if not all, of the dietary compounds are derived from plants and often denoted as phytochemicals. Recent cell line-based ex vivo and animal model-based in vivo studies have further validated the chemopreventive as well as tumoricidal effects of these phytochemicals [5-7]. Phytochemicals come in many different, structurally-defined, flavors such as polyphenols, flavonoids, terpenoids, saponins, anthocyanins, phytosterols, isothiocyanates, or organo-sulfur compounds. Irrespective of their structural differences, many of these compounds possess significant chemopreventive and chemotherapeutic effects against many cancers [1,8-10]. As these chemopreventive/ anticarcinogenic agents are quite diverse in their structural chemistry and bioactivity, assessing their efficacy based on their signaling mechanisms is critical for the development of potential prophylactic and/or therapeutic agents for cancer [11].

Thymoquinone, abbreviated hereafter as TQ, is one such phytochemical, derived primarily from the seeds of Nigella sativa [12]. The seeds of $N$. sativa, commonly known as black cumin, have been used as a herbal medicine for more than 2000 years [12-14]. While various formulations of $N$. sativa have been used to treat many different diseases including cancer, TQ has been identified as the principal bioactive component that contributes to health benefits of $N$. sativa [1215]. Defining the etiological features associated with cancer, ten critical alterations in cell physiology have been defined as the hallmarks or of cancer. They are: (1) sustained proliferative signaling; (2) insensitivity to growth inhibitory signals; (3) invasion and metastasis; (4) limitless replicative potential; (5) tumor angiogenesis; (6) resistance to cell death; (7) eva-

Received August 3, 2020, Revised September 11, 2020, Accepted September 14, 2020 Correspondence to Danny N. Dhanasekaran, E-mail: danny-dhanasekaran@ouhsc.edu, https://orcid.org/0000-0001-6350-8926

(i) \$ This is an Open Access article distributed under the terms of the Creative Commons Attribution Non-Commercial License, which permits unrestricted noncommercial use, distribution, and reproduction in any medium, provided the original work is properly cited. 
sion of immune destruction; (8) tumorigenic inflammation; (9) genomic instability; and (10) reprogramming of energy metabolism [16-18]. TQ has been shown to exert its chemopreventive and anticancer effects by inhibiting all of the major pathways involved in the manifestation of cancer hallmarks and their enabling characteristics [19]. Recent studies have provided insights into the mechanism by which TQ modulates the different cancer-enabling characteristics in order to suppress cancer cell growth, proliferation, invasive migration, and cancer progression. While the mechanistic roles of phytochemicals such as curcumin, epigallocatechin gallate, and resveratrol in chemoprevention have been extensively reviewed [20-22], such information is rather limited in the case of TQ. Considering the multi-targeted chemopreventive and anticancer effects of TQ, the focus of this review is to provide a comprehensive update on the molecular mechanisms underlying the chemopreventive, chemotherapeutic, and anticancer effects of $\mathrm{TQ}$.

\section{REDOX CYCLING AND ANTICANCER ACTIVITY OF TQ}

$T Q$, bearing the chemical formula $\mathrm{C}_{10} \mathrm{H}_{12} \mathrm{O}_{2}$, is chemically defined as 2-isopropyl-5methyl-1,4-benzoquinone (Fig. 1). Although TQ was originally isolated from $N$. sativa, it is also present in many other plants [23]. As a typical quinone compound, TQ can undergo both enzymatic and non-enzymatic redox cycle reactions, giving rise to pro-oxidant as well as anti-oxidant derivatives [24,25]. One electron reduction of TQ by an enzyme complex consisting of NADPH cytochrome p450 reductases, $\mathrm{NADH}$ cytochrome $\mathrm{b}_{5}$ reductase, and NADPH ubiquinone oxidoreductase can generate semiquinone and TQ-dianion with pro-oxidant activity. In addition, neutral $\mathrm{pH}$ and low intracellular concentration of TQ appear to favor the formation of pro-oxidative semiquinone [26].

As opposed to the one-step one electron reduction that generates the pro-oxidative derivatives of $\mathrm{TQ}$, a two electron reduction of TQ by NADPH quinone oxidoreductase or further reduction of semiquinone by NADPH cytochrome p450 reductases, cytochrome $b_{5}$ reductase, and NADPH ubiquinone

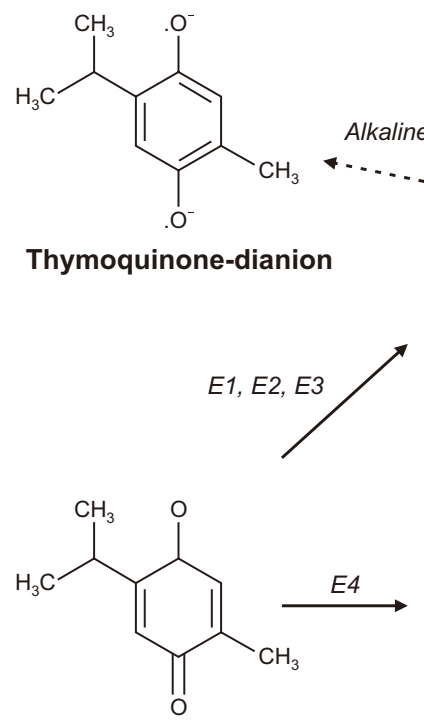

Thymoquinone<smiles>Cc1cc(O)c(C(C)C)cc1[O-]</smiles>

Semiquinone

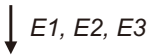<smiles>Cc1cc(O)c(C(C)C)cc1O</smiles>

Thymoquinone

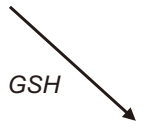<smiles>Cc1c(O)cc(C(C)C)c(O)c1[Si]</smiles>

Pro-oxidant

Anti-oxidant

Glutathionylated-dihydrothymoquinone

Figure 1. Redox cycle of thymoquinone (TQ). One electron reduction of TQ by NADPH cytochrome p450 reductases (E1), cytochrome $b_{5}$ reductase $(E 2)$, and NADPH ubiquinone oxidoreductase (E3) generates semiquinone with pro-oxidant activity. In alkaline $\mathrm{pH}$ (mostly in vitro) semiquinone is converted further into TQ-dianion with pro-oxidant activity. One-step two electron reduction of TQ by NADPH cytochrome p450 reductases $(E 1)$, cytochrome $b_{5}$ reductase $(E 2)$, and NADPH ubiquinone oxidoreductase $(E 3)$ generates thymohydroquinone with anti-oxidant activity. TQ can also undergo a non-enzymatic reduction through its interaction with glutathione (GSH) forming glutathionyl-dihydrothymoquinone with antoxidant activity. 
oxidoreductase can generate thymohydroquinone with potent anti-oxidant activity [25-28]. TQ can also undergo a non-enzymatic reduction through its interactions with glutathione forming glutathionyl-dihydrothymoquinone in physiological conditions [29]. It has been observed that the glutathionyl-dihydrothymoquinone can act as an anti-oxidant capable of scavenging organic free radicals $[29,30]$.

It appears that the cellular and/or physiological context(s) determines whether TQ acts as a pro-oxidant or an anti-oxidant in vivo. Since TQ has been used in a wide range of concentrations in many of the reported ex vivo (2 to $100 \mu \mathrm{M})$ as well as in vivo (5 to $20 \mathrm{mg} / \mathrm{kg}$ ) studies [23], it has become challenging to distinguish the pro versus anti-oxidant effects of TQ in eliciting the observed anticancer response. Nevertheless, it should be stressed that both the pro-oxidant and the anti-oxidant derivatives of TQ have been observed to elicit anticancer response through different signaling mechanisms [31]. Thus, the redox cycling of TQ indeed plays a major role in the contextual modulation of different oncogenic pathways by $T Q$.

\section{PRO-OXIDANT ROLE OF TQ IN CHEMOPREVENTION}

A number of studies have documented the role of the pro-oxidant activity of TQ in its chemopreventive and anticancer activities [26,32]. Conversion of TQ into semiquinone is accompanied by the release of reactive oxygen species (ROS) that include superoxide, peroxide, and hydroxyl radicals. TQ-generated ROS causes oxidative stress, mitochondrial and nuclear damage, and subsequent cell-death. This has been demonstrated in many different cancer cells including those from adult T-cell leukemia [33], prostate [34], hepatocellular carcinoma (HCC) [35], skin [36,37], breast [38], kidney [39,40], renal cell carcinoma [39], and ovarian cancer [41]. The pro-oxidant property of TQ is also observed to modulate the ionic status of the transition metal ion copper, so as to promote cell death in prostate cancer cells [34]. In addition, the ROS generated by TQ is also involved in modulating multiple signaling pathways to promote its anticancer activity. In $\mathrm{HCC}$, the pro-oxidant activity of TQ has been shown to be involved in inducing apoptosis by stimulating the increased expression of several pro-apoptotic proteins including TNF-related apoptosis-inducing ligand (TRAIL), TRAIL-receptor 2 (TRAILR2)/death receptor 5, caspase 9, caspase 8 , caspase 3 , and B-cell lymphoma-x-Small (Bcl-xS) while concomitantly inhibiting the expression of the antiapoptotic B-cell lymphoma-2 (Bcl-2) [35,42].

Similarly, TQ-induced ROS generation is involved in promoting apoptosis in primary effusion lymphoma cells by inhibiting AKT [43]. In prostate cancer cells, TQ-generated ROS has been demonstrated to play a role in the downregulation of androgen receptors as well as anti-apoptotic proteins along with increased expression of apoptosis-inducing factor-1 to induce growth arrest and apoptosis [44]. In A431 epidermoid carcinoma cells, TQ-induced apoptosis involves ROS-dependent inactivation of Src kinase (Src) and the downstream transcription factor, STAT3. In light of the previous findings that ROS can rapidly inactivate Src [45], the pro-oxidative activity of TQ targets cancer cells by more than one mechanism.

\section{ANTI-OXIDANT ROLE OF TQ IN CHEMOPREVENTION}

The anti-oxidant activity of TQ has been shown to play a chemopreventive role in many cancer models including prostate, colon, and hepatic cancers [46-49]. TQ has been reported to inhibit tumor development and progression induced by oxidative-stress induced colon tumorigenesis by 1,2-dimethyl-hydrazine in murine models of colon cancer $[47,48]$. In this model, the anti-oxidant role of TQ involves its inhibition of the tumorigenic generation of superoxide anions and nitric oxide as well as its role as a scavenger of carcinogenic free radicals [47]. Furthermore, TQ has been shown to induce the expression of several cytoprotective anti-oxidant enzymes involving catalases, superoxide dismutase, reduced glutathione, glutathione peroxidase, glutathione-S-transferases, and glutathione reductase that can combat the oxidative stress-induced tumorigenesis [50,51].

Anti-oxidant activity of TQ has also been attributed to its inhibitory effect on diethylnitrosamine-induced hepatic carcinogenesis through a similar upregulation of anti-oxidant enzyme levels [49]. In addition, the anti-oxidant effect of TQ is also associated with the ability of TQ to suppress the adverse effects of chemotherapeutic agents such as cyclophosphamide [52], cisplatin [53,54], and doxorubicin [55] in non-cancerous cells and tissues [26]. Thus, TQ-mediated increase in the levels of anti-oxidant enzyme plays a significant role in the oxidative stress-induced tumorigenesis and chemically induced carcinogenesis as well as the cytoprotection against chemotherapeutic toxicity [56].

\section{EFFECT OF TQ ON CANCER CELL PROLIFERATION}

TQ inhibits cell proliferation by controlling key cell cycle checkpoints and inducing cell cycle arrest at G0/G1, G1/G2, or G2/M phases through a variety of mechanisms (Fig. 2). In Jurkat cells representing acute T-cell leukemia, TQ induces G0/G1 phase cell cycle arrest [57]. TQ induces G1/S cell cycle arrest in many other cancer cells including those of colorectal cancers [58], lung cancer [59], HCC [60], and prostate cancer [61]. In cell-lines derived from cholangiocarcinoma, TQ induces G2/M cell cycle arrest [62-64]. In many breast cancer cell lines including those derived from triple negative breast cancer, TQ induces G0/G1, G1/S, or G2/M phase cell cycle arrest in a cell type dependent manner [65-70]. 


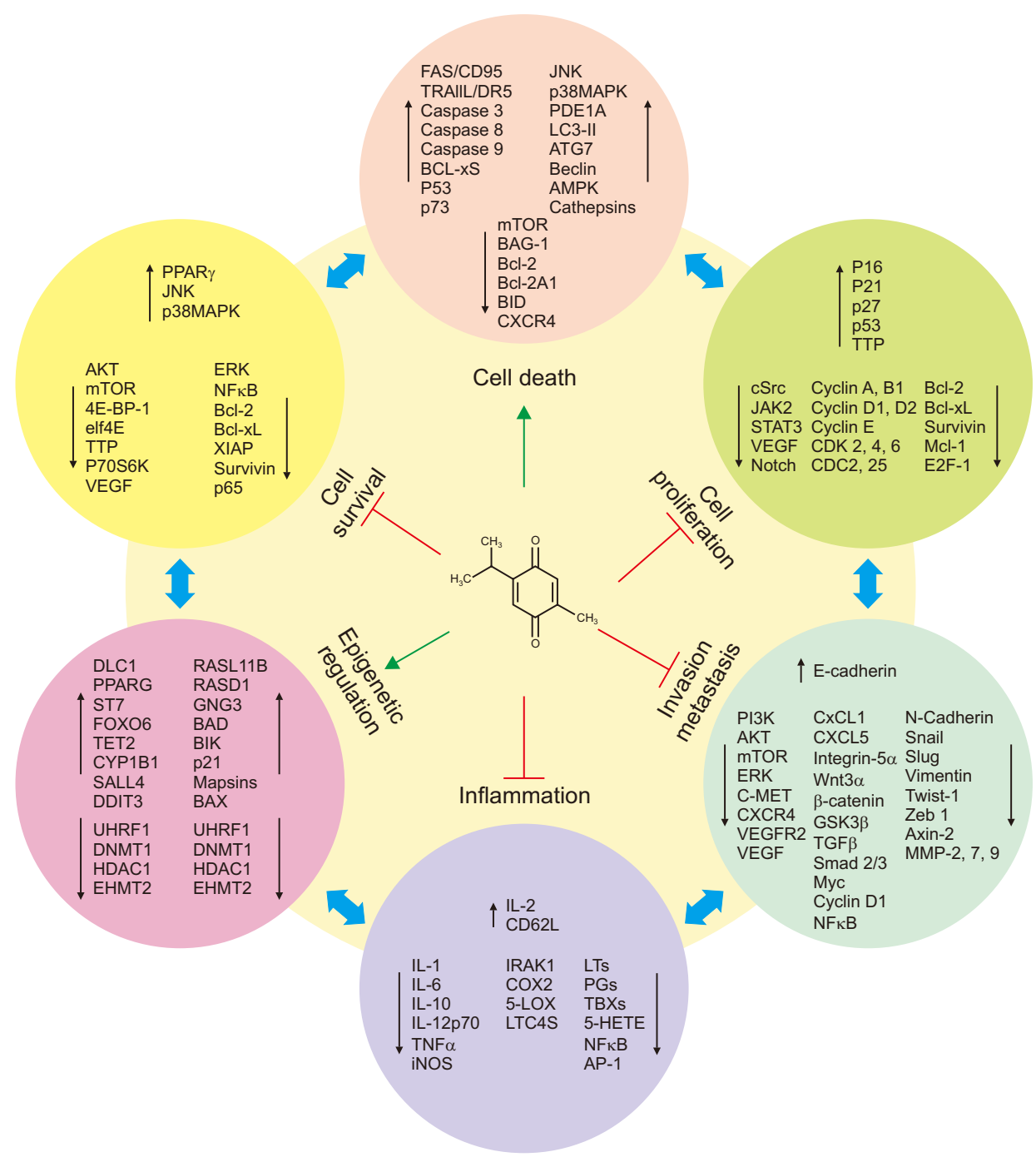

Figure 2. Anticancer activity of thymoquinone (TQ). As a multi-target chemopreventive phytochemical, TQ exerts its anticancer activity through the modulation of expression as well as activation profile of critical signaling molecules involved in cancer cell growth and progression. Signaling molecules upregulated or downregulated by TQ in its anticancer activity is depicted by the upwards $\uparrow$ or downwards $\downarrow$ arrows. By regulating the overlapping pathways involved in cell proliferation, cell survival, cell death, invasive metastasis, and inflammatory signaling through multiple mechanism including epigenetic regulation, TQ strongly inhibits cancer growth, progression, and metastasis (detailed in the text). JNKs, C-Jun $\mathrm{N}$-terminal kinases; MAPK, modulation of the mitogen-activated protein kinase; elF4E, eukaryotic translation initiation factor 4E; TTP, tristetraprolin; ERK, extracellular signal-regulated kinases; Bcl-2, B-cell lymphoma-2; Bcl-xS, B-cell lymphoma-x-Small; XIAP, X-linked inhibitor of apoptosis; TRAIL, TNF-related apoptosis-inducing ligand; DR5, death receptor 5; PDE1A, phosphodiesterase 1A; AMPK, AMP-activated kinase; BID, BH3interacting domain death protein; CXCR4, CXC-motif chemokine receptor-4; JAK2, Janus kinase; CDK, cyclin-dependent kinases; CDC, cell division cycle; E2F-1, Early 2 Family-1; UHRF1, ubiquitin-like-containing PHD and RING finger domains; DNMT1, DNA methyltransferase 1; HDAC1, histone deacetylase 1; EHMT2, euchromatic histone lysine methyltransferase 2; IL, interleukin; iNOS, inducible NOS; IRAK1, interleukin-1 receptorassociated kinase 1; 5-LOX, 5-lipoxygenase; LTC4S, leukotriene C4 synthase; LTs, leukotrienes; PGs, prostaglandins; TBX, thromboxanes; 5-HETE, 5-hydroxyeicosatetraenoic acid; PI3K, phosphatidylinositol-3-kinase; VEGFR, VEGF-VEGF-receptor; CXCL, CXC-motif ligand; GSK3 $\beta$, glycogen synthase kinase $3 \beta$; MMP, matrix metalloproteinase.

The primary mechanism through which $\mathrm{TQ}$ exerts its antiproliferative effects involves the downregulation of cyclin $A$ [61], cyclin D1 [37,66,71-73], cyclin D2 [73], cyclin E [66], and cyclin-dependent kinases (CDK) along with the increased expression of CDK inhibitors, such as p16 [71], p21 [61,74], and p27 $[61,66]$. For instance, TQ has been shown to induce G1 cell cycle arrest as well as radiosensitization [75] by in- hibiting key proteins, such as CDK2 and CDK4/CDK6 [6567]. On the other hand, TQ-treated LNCaP prostate cancer cells demonstrated a decrease in E2F-1 transcription factor regulated proteins and cyclin $A$ with $\mathrm{G} 1 / \mathrm{S}$ phase cell cycle arrest [61]. In neuroblastoma cells, TQ-induced G2/M cell cycle arrest is associated with the decreased expression of proliferating cell nuclear antigen, cyclin B1, and CDK1 along 
with the increased expression of p53 and p21 [76]. In doxorubicin-resistant breast cancer cells and spindle carcinoma cells, TQ induces G2/M arrest that can be associated with the decreased expression of cyclin B1 and cell division cycle 25/Cdc25 phosphatase levels and increased expression of p53 $[77,78]$. In HCC cells, TQ has been shown to induce G0/G1 cell cycle arrest by inhibiting the expression of cyclin $\mathrm{D} 1, \mathrm{CDK} 2$ and $\mathrm{Bcl}-2$ while increasing the expression of p21 through a pathway involving the downregulation of Notch signaling [60].

STAT3-signaling is another signaling node targeted by TQ for the inhibition of cell proliferation. TQ modulates STAT3 signaling in colon cancer cells and multiple myeloma cells so as to inhibit oncogenic signaling and proliferation $[70,73,79]$. In these cells, TQ has been shown to inhibit the expression and/or the activities of STAT3, Src, Janus kinase-2 phosphorylation, cyclin D1, Bcl-2, B-cell lymphoma-x-Large (Bcl$x L$ ), survivin, myeloid cell leukemia sequence $1 / \mathrm{Mcl}-1$ and VEGF $[70,73,79]$. TQ can also inhibit cell proliferation by stimulating the expression of tristetraprolin (TTP), a tumor suppressor involved in the stability of diverse mRNAs [80]. TTP exerts its tumor suppressive role by binding to the adenylate-uridylate-rich elements at the 3'-untranslated region of many oncogenic mRNAs and accelerating their rapid decay by recruiting an enzyme involved in the shortening of their $\operatorname{poly}(A)$ tails $[81,82]$. Interestingly, the list of mRNAs targeted by TTP for accelerated decay includes those of cyclins, CDKs, and E2F-1 [82], all of which show decreased expression following TQ-treatment. Thus, TTP appears to provide a pivotal mechanism through which $\mathrm{TQ}$ can downregulate cyclins and CDKs to induce cell cycle arrest.

\section{TQ-MEDIATED INHIBITION OF CANCER CELL SURVIVAL}

A large number of studies have established the inhibitory role of TQ in cancer cell survival [15,31]. Cell survival depends on the balance between cell proliferation and apoptosis. TQ has been found to inhibit the survival of many cancer cells derived from breast cancers [65,67,77,83], pancreatic cancer [84], gastric cancer [85], primary effusion lymphoma [43], prostate cancer [86,87], kidney cancer [88], squamous cell carcinoma [89], renal cell carcinoma [90], and cholangiocarcinoma [63], primarily through attenuation of the activity of AKT, a crucial kinase associated with cell survival. TQ inhibits the activation of AKT through ROS-dependent mechanisms and/or through activation of the lipid phosphatase, phosphatase and tensin homolog (PTEN). In primary effusion lymphoma cells, it has been shown that the inhibition of AKT by TQ requires the generation of ROS [43]. Results from breast, gastric, and pancreatic cancer cells indicate that $\mathrm{TQ}$ stimulates the expression of PTEN. PTEN, in turn, dephosphorylates and downregulates the activity of phosphatidylinositol-3-kinase (PI3K) with the resultant decrease in the activation of downstream AKT and its effectors $[77,84,85]$. Considering the critical role of AKT in the vast array of cell survival signaling pathways, the inhibitory effect of TQ on the activity of AKT is reflected on multiple signaling nodes downstream of AKT. In breast cancer, the inhibition of AKT by TQ results in the dysregulated phosphorylation of mTOR [84,91], eukaryotic translation initiation factor 4E/elF4E, eukaryotic translation initiation factor 4E-binding protein 1/4E-BP1, and ribosomal protein S6 kinase $\beta 1 /$ p70S6 kinase $[66,86]$, contributing to an overall reduction in cell survival.

In conjunction with the inhibition of the PI3K-AKT pathway, TQ-mediated inhibition of cell survival involves the upregulation of pro-apoptotic proteins, such as $\mathrm{Bcl}-2$-Associate $\mathrm{X}$ protein (Bax) along with the downregulation of anti-apoptotic proteins, such as $\mathrm{Bcl}-2, \mathrm{Bcl}-\mathrm{xL}, \mathrm{X}$-linked inhibitor of apoptosis (XIAP), and survivin [66,84]. In addition to AKT-signaling, TQ also attenuates NF- $\mathrm{B}$ B signaling to reduce cell survival. For instance, TQ has been shown to reduce the expression levels of AKT through a pathway involving NF-KB, microRNA-603, and eukaryotic elongation factor-2 kinase. Interestingly, in a parallel pathway, TQ has also been shown to induce the expression of pro-apoptotic proteins via PPAR- $\gamma$ in breast cancer cell lines [92]. TQ has been reported to induce the expression of PPAR- $\gamma$ in diverse cellular contexts [92,93]. In breast cancer cells, TQ-mediated activation of PPAR- $\gamma$ leads to the downregulation of the expression of the pro-survival genes Bcl-2 and BCL-xL [92]. Based on in-silico analyses, it has also been postulated that TQ can potentially interact with PPAR- $\gamma$ [92], thereby promoting PPAR- $\gamma$-mediated inhibition of cell survival pathways.

Additionally, TQ-mediated inhibition of cell survival often involves the modulation of the mitogen-activated protein kinase (MAPK)-family of kinases including extracellular signal-regulated kinase (ERK), c-Jun N-terminal kinase (JNK), and p38 MAPK. While ERKs are often associated with cell survival and proliferation, JNK and p38 MAPK are primarily involved in apoptotic signaling pathways. Consistent with this general signaling paradigm, TQ has been shown to inhibit the activity of ERKs in many cancer cells, such as those derived from myeloma [94] squamous cell carcinoma [89], prostate cancer $[95,96]$, breast cancer [97], and breast cancer xenografts [38] while activating JNKs and/or p38MAPKs in colon [98], prostate [44], and pancreatic cancer cells [99]. TQ also controls cancer cell survival by modulating the signaling activity of NF$\kappa \mathrm{B}$. In HS766T pancreatic ductal adenocarcinoma cells, TQ inhibited the translocation of the $\mathrm{NF}-\kappa \mathrm{B}$ transcription factor into the nucleus. Other effects of $\mathrm{TQ}$ on the $\mathrm{NF}-\mathrm{kB}$ pathway include its inhibitory role in TNF-induced degradation of the inhibitory subunit of $\mathrm{NF}-\kappa \mathrm{B} \alpha$, inhibition of $\mathrm{p} 65$ activation via phosphorylation, and nuclear translocation [100,101]. TQ also potentiated the anticancer effect of bortezomib in multiple myeloma cells by downregulating the VEGF, Bcl-2 and p65 expression [102]. Thus, the inhibition of cancer cell survival by $T Q$ is mediated by its modulatory effects on multiple 
pro-survival signaling nodes in addition to the activation of anti-survival mechanisms. It should be pointed out that these multitargeted effects of TQ are not mutually exclusive. Rather, they form an array of overlapping, permissive, and/or synergistic effects that collectively contribute to the cumulative inhibition of cancer cell survival.

\section{INDUCTION OF APOPTOTIC CELL DEATH IN CANCER CELLS BY TQ}

In addition to its inhibitory effect on cell proliferation and survival, TQ promotes apoptosis of cancer cells (Fig. 2). TQ-induced apoptosis often results in restoring the dysregulation of apoptosis-associated gene expression [103]. TQ promotes both intrinsic and extrinsic apoptotic cell death through multiple mechanisms. A plethora of evidences indicate that TQ induces intrinsic apoptotic cell death by downregulating the expression of Bcl-2-family of anti-apoptotic proteins as well as through the induction of mitochondria-dependent activation of caspases. This has been exemplified in many cancer cells including those of neuroblastoma [104], myeloblastic leukemia [105], breast carcinoma [77], primary effusion lymphoma [43], lymphoblastic leukemia [57], colon cancer [98], hepatic cancer [106], and osteosarcoma cell lines [107]. TQ's ability to downregulate the expression of Bcl-2 family of anti-apoptotic proteins is well characterized in prostate cancer cells in which TQ-treatment leads to the drastic reduction in the expression of several anti-apoptotic proteins belonging to the $\mathrm{Bcl}-2$ family including Bcl-2, B-cell lymphoma 2-related protein A1/ $\mathrm{Bcl}-2 \mathrm{~A} 1, \mathrm{Bcl}-\mathrm{xL}$, and $\mathrm{BH} 3$ Interacting-domain Death agonist protein/BH3 Interacting-domain Death agonist protein leading to the activation of caspases [44].

The mechanisms underlying the activation of caspases by $T Q$ is very much cell type dependent. In bladder cancer cells, it has been shown that TQ induces endoplasmic reticulum (ER) stress and subsequent action of an ER-stress related signaling pathway leading to mitochondrial dysfunction and caspase 9-mediated activation of caspase 3 [108]. In leukemia-derived HL60 cells, TQ activates caspase 3 via the upstream caspase 8 and mitochondrial release of cytochrome $c$ [105]. A similar mitochondrial pathway involving cytochrome-release and caspase 9-caspase 3 activation has been ascribed to TQ-induced apoptosis in both the p53-null MG63 and p53-mutated MNNG/HOS osteosarcoma cell lines [107]. In addition, TQ-associated ROS activity also plays a role in inducing apoptotic cell death via p53. In HCT116 colorectal cancer cells and MCF-7 breast cancer cells, it has been shown that the ROS-activity of TQ inflicts DNA-damage, which leads to the upregulation $\mathrm{p} 53$, and the increased expression of p53-target genes involved in apoptosis or growth inhibition $[78,109,110]$. TQ has been shown to induce apoptosis of p53-null or p53-mutated cancer cells through activation of caspases, independently of p53.

Pertaining to the role of $T Q$ in extrinsic apoptosis, it has been noted that TQ promotes Fas/cluster of differentiation-95-death receptor-induced apoptosis in multiple myeloma cells [94]. TQ-treated multiple myeloma cells exhibited significant downregulation of CXC-motif chemokine receptor-4 (CXCR4) expression along with the inhibition of chemokine CXC-motif ligand (CXCL)12-mediated chemotaxis that led to the increased sensitivity of these cells to Fas-/ CD-95-receptor mediated cell death [94]. Studies using HCC cell lines as well as HCC tissue from a murine model have shown that TQ stimulates TRAIL and TRAILR-2-mediated apoptotic signaling by eliciting the increased expression of TRAIL, TRAILR2, caspase 9, caspase 8, caspase 3, and Bcl$\mathrm{xS}$. TQ potentiates this pathway further by decreasing the expression of Bcl-2 in HCC. TQ-generated ROS has been implicated in initiating this pathway in $\operatorname{HCC}[35,42]$.

TQ has also been observed to induce apoptosis through several other alternative apoptotic signaling pathways. One such mechanism involves the activation of tumor suppressor p73, a structural and functional homologue of p53 [111]. In lymphoblastic leukemia derived Jurkat cells, TQ has been shown to increase the levels of p73 either via ROS-mediated DNA-damage pathway or by inhibiting the expression of phosphodiesterase $1 \mathrm{~A}[57,69]$. It has been well characterized that $\mathrm{p} 73$ can induce apoptosis through transactivation of many different proapoptotic genes, involved in both intrinsic and extrinsic apoptotic pathways [111,112]. In addition, p73 is known to induce apoptosis through transcription-independent mechanisms including the epigenetic de-repression of proapoptotic genes [112].

\section{INDUCTION OF AUTOPHAGIC CELL DEATH IN CANCER CELLS BY TQ}

In addition to pro-apoptotic mechanisms, TQ promotes cell death in cancer cells via autophagy. Autophagy is emerging as a double-edged sword in cancer biology [22,113,114]. In a context-specific manner, autophagy suppresses tumor growth in specific instances or promotes cancer cell growth and survival. The anticancer effects of TQ has been documented in in both of these pathobiological contexts. TQ-mediated autophagic cell death involves the context-specific inhibition or induction of autophagy. In the head and neck squamous cell carcinoma-derived SASVO3 cell-line, TQ induces cancer cell death via pathways involving both caspase-dependent apoptosis and microtubule-associated protein 1A/1B-light chain $3 /$ LC3-II activation-dependent autophagy [115]. In these cells, TQ inhibits the activation of $\mathrm{mTOR}$, a negative regulator of autophagy while simultaneously stimulating the expression of autophagic markers, such as LC3-II and Beclin-1. This is also consistent with the observation that $\mathrm{TQ}$ induces autophagic cell death in renal carcinoma derived 786-O and ACHN cell lines via the upregulation of AMP-activated kinase along with the downregulation of mTOR activity and increased expression of LC3-II [116]. Increased autophagic cell death has also 
been observed to synergize with the caspase-dependent apoptotic cell death in SASVO3 cells. A similar role for TQ in inducing both apoptotic and autophagic cell death with the resultant potentiation of the anti-proliferative effects of Gemcitabine has been noted in MCF7 breast cancer cells [117]. In LoVo colon cancer cells, TQ can induce autophagic cell death through pathways involving the activation of JNK and p38 MAPK [118]. In these cells TQ promotes mitochondrial outer membrane permeabilization-mediated mitophagy and increased expression of several autophagic as well as mitophagic proteins that results in autophagic cell death [118].

In cells that utilize autophagy as a survival mechanism, such as those from glioblastoma multiforme (GBM), TQ promotes cell death by inhibiting autophagy. Using GBM-derived U87MG cell line, it has been shown that TQ enhances the anti-proliferative effects of Temozolomide through inhibition of autophagy [119]. In this cell line, TQ induced cell death by inhibiting the expression of autophagy-associated proteins Beclin-1 and autophage-related 7/ATG7 at the transcriptional level. It has also been observed that TQ-induced cell death through the inhibition of autophagy in GBM-derived cell lines could also involve a cathepsin-B-dependent mechanism [120]. In GBM-derived U87MG and Gli36 $\triangle E$ EGFR cell lines, TQ-induced lysosomal membrane permeabilization leads to the inhibition of autophagic flux, release of cathepsins to cytosol, and the resultant execution of cell death by cathepsin-B.

\section{EFFECT OF TQ ON CANCER CELL MIGRATION, INVASION, AND TUMOR ANGIOGENESIS}

Many of the signaling nodes targeted by TQ in inhibiting the survival and proliferation of the cancer cells are also involved in cancer cell migration, invasion, and tumor angiogenesis (Fig. 2). TQ was demonstrated to inhibit epithelial to mesenchymal transition (EMT) in many cancer cells including those from breast cancer [121], bladder cancer [122,123], cervical cancer [124], gastric cancer [91], and prostate cancer [125]. $\mathrm{TQ}$ has been shown to reverse EMT in bladder cancer as well as gastric cancer cells by strongly attenuating the $\mathrm{PI} 3 \mathrm{~K} /$ AKT/mTOR signaling activity and downregulating the expression of key signaling components of the EMT pathway, such as $\mathrm{N}$-cadherin, Snail, Slug, vimentin, Twist1, and $\beta$-catenin [91,122]. In bladder cancer cells, TQ promotes the reversal of EMT by inhibiting the Wnt $3 \alpha / \beta$-catenin/glycogen synthase kinase $3 \beta$ (GSK3 $\beta$ ) signaling axis [123]. By inhibiting this signaling axis, TQ also downregulates the expression of downstream Myc, Axin-2, matrix metalloproteinase (MMP)-7, cyclin D1 and c-MET that are critically involved in EMT and invasive migration of cancer cells. Similarly, it has been shown that TQ inhibits EMT-specific transcription factors such as Twist1 and Zeb 1 in cervical cancer cells [124]. In prostate cancer cells, $\mathrm{TQ}$ represses the expression of EMT markers by inhibiting TGF- $\beta / S M A D 2 / 3$ signaling [125]. Thus, TQ reverses EMT through targeted inhibition of several upstream signaling nodes that promote the expression of the critical players of EMT in a cancer and/or cell-type specific manner. The potent inhibitory effect of TQ on EMT results in the attenuation of migration and invasion of cancer cells irrespective of their etiology or cell-type. This is further substantiated by the in vivo mouse model studies. In a breast cancer xenograft mouse model, it was observed that TQ drastically reduced Twist1-induced metastasis by inhibiting the expression of EMT associated $\mathrm{N}$-cadherin and stimulating the expression of E-cadherin [121].

The inhibitory effects of TQ also span other signaling nodes in invasive cell migration. It has been recognized that TQ hinders the migration and metastasis of glioblastoma cells by suppressing the activities of Focal adhesion kinases and ERKs, thus inhibiting the downstream MMP-9, MMP-2 that are involved in the invasive migration of cancer cells [126]. In the case of breast cancer cells, TQ exerts its inhibitory effect on metastasis by downregulating the stimulators of EMT and invasive migration such as TGF- $\beta$, MMP-9, MMP-2, and integrin- $5 \alpha$ while upregulating the expression of the inhibitors of metastasis such as E-cadherin [127]. TQ also inhibits bone metastasis of breast cancer cells by blocking the activation of $\mathrm{NF}-\kappa \mathrm{B}$, thereby repressing the $\mathrm{CXCR} 4$-signaling axis [128]. TQ-induced TTP can also play a role in attenuating the expression of metastasis-specific genes, as in the case of proliferation-specific genes by accelerating the decay of the metastasis-specific mRNAs $[80,82]$. It has been shown that TQ inhibits the migration, invasion, and EMT of renal cell carcinoma cell lines by inducing autophagy [116].

In addition to its effect on EMT and invasive metastasis, $\mathrm{TQ}$ potently downregulates the expression of the key antiangiogenic molecules, thus impeding tumor angiogenesis. Both in vitro and in vivo studies have shown that $\mathrm{TQ}$ blocks tumor angiogenesis effectivity by blunting the activity of VEGF in many different cancers. TQ attenuates tumor angiogenesis by inhibiting the expression of VEGF as well as the signaling pathways stimulated by VEGF. TQ also downregulates the expression VEGF in several different cell lines derived from gastric carcinoma [129], osteosarcoma [130], colon carcinoma [131], cholangiocarcinoma [63], prostate cancer cells [95], multiple myeloma cells [101,102], and leukemia [70]. In addition to VEGF, TQ has been shown to inhibit the expression of several other angiogenic chemokines, such as CXCL5/ ENA-78 and CXCL1/Gro-alpha cytokines in non-small lung cancer and small cell lung cancer cell lines [59]. Both in vivo and invitro analyses have shown that the effect of TQ on VEGF expression is primarily due to its inhibitory effect on the activation of $\mathrm{NF}-\kappa \mathrm{B}$, which is involved in the regulation of several angiogenic genes including VEGF $[130,131]$. In addition to its direct effect on the expression of VEGF that can have significant negative impact on the angiogenic signaling in the endothelial cells in the tumor vasculature, TQ also inhibits the signaling pathways downstream of VEGF-VEGF-receptor 
(VEGFR) in tumor associated endothelial cells. Using both a prostate cancer xenograft based in vivo mouse model and a human umbilical vein endothelial cells (HUVEC) based ex vivo model, it has been shown that TQ inhibits tumor angiogenesis and arrests prostate cancer growth [95]. TQ also inhibits the proliferation as well as migration of human endothelial cells. Using HUVEC cells, it has also been demonstrated that TQ inhibits VEGFR-mediated activation of ERK and AKT in these cells, rather than by directly inhibiting VEGFR2 receptor activation [95]. Thus, TQ mediated inhibition of angiogenesis occurs at two different tiers in the two distinct cellular components of the tumor microenvironment. In cancer cells TQ downregulates the expression of VEGF and other angiogenic growth factors. In tumor associated endothelial cells, TQ inhibits the activation of signaling pathways downstream of VEGFR.

\section{ANTI-INFLAMMATORY ROLE OF TQ}

Inflammatory signaling has been identified as a causative factor in the genesis and progression of many cancers. As an anticancer agent, TQ potently inhibits both the cellular and the organismal inflammatory responses [132,133] (Fig. 2). Inflammatory response mainly involves the synthesis and release of the eicosanoids, such as prostaglandins (PGs), thromboxanes (TBX), and leukotrienes (LTs) that act as the mediators of inflammation. While COX converts arachidonic acid (AA) into PGs and TBXs, lipoxygenase (LOX) converts AA into LTs. Experimental evidence indicates that TQ inhibits the generation of the eicosanoids by inhibiting the COXs as well as LOXs [134]. In the case of LTs, TQ shuts down the synthesis of LTs by inhibiting the activities of 5-LOX, 5and LT C4 synthase [135]. TQ inhibits the synthesis of PGs and TBXs by downregulating the expression of COX2 by targeting the upstream interleukin-1 receptor-associated kinase 1 (IRAK1) [136]. By targeting the activity as well as the degradation of IRAK1, TQ downregulates the transcriptional activities of NF-KB and activator protein 1/AP1, which are collectively required for the transcriptional activation of COX-2 expression. In fact, through inhibition of the IRAK1-mediated signaling, TQ also downregulates the expression of many other inflammatory cytokines and signal mediators, such as interleukin (IL)-1, IL-6, TNF $\alpha$, and inducible NOS [136]. It is noteworthy that the anti-oxidant activity of TQ can also play a role in attenuating cellular inflammatory response. Cytokine-induced generation of ROS has been shown to play a significant role in the synthesis of the inflammatory eicosanoids from AA through the activation and/or expression of the critical upstream signaling molecules including AKT and $N F-\kappa B$ [137]. Since the anti-oxidant activity of TQ is known to scavenge the free radicals [47], this could lead to the attenuation of inflammatory response through the inhibition of eicosanoid synthesis.

\section{IMMUNOMODULATORY ROLE OF TQ}

Owing to the overlapping pathways involved in inflammatory response and immunomodulation, TQ has significant immunomodulatory effects. Potentially, TQ could suppress inflammation-induced immuno-suppression through its negative impact on the pro-inflammatory eicosanoid synthesis and NF-kB mediated gene expression [138]. While several lines of evidence attest to this potential of TQ, they are primarily derived from the use of $N$. sativa extract or oil rather than from the use of TQ alone $[133,139,140]$. Thus, there is a paucity of information on the immunomodulatory role of $T Q$ in relation to its anticancer activity. However, a small set of studies using TQ has indicated that TQ can modulate both innate and adaptive immune responses [133]. With its potent inhibitory effect on the activity or the expression of different inflammatory cytokines and their effector molecules, TQ can modulate different aspects of cellular as well as humoral immunity [133]. Cellular immune responses modulated by TQ include dendritic cell maturation, NK-cell cytotoxicity, phagocytic activity, chemotaxis, and T cell activation $[141,142]$. The effect of TQ on the specific immune response appears to be context-specific. For instance, TQ inhibits lipopolysaccharide-induced maturation of dendritic cells by blunting the expression of IL-10, IL-12, and TNF $\alpha$ along with the activation of caspase $3 / 8$ and increasing annexin $V$ binding [141]. On the contrary, TQ rescued T cell activation and the associated immune response in the Streptozotocin-treated mouse model by stimulating IL-2 and T cell proliferation [143].

An immunomodulatory role of $T Q$ was also demonstrated by the observation that TQ stalls and overcomes pesticide-induced reduction in immunoglobulin levels, leukocyte numbers, and phagocytic activities of macrophages in in a rat model system [144]. Although these studies do not directly correlate with the potential anticancer immunity of $T Q$, they do point out the immunoregulatory function of $T Q$ and its therapeutic potential in cancer immunotherapy. A case in point is the observation that $T Q$ enhances the survival of antigen-specific CD8-positive T cells along with the sustained expression of the homing receptor cyclical expression of L-selectin/L-selectin, which could have a significant impact in expanding cluster of differentiation-8/CD8- and/or L-selectin-positive T cells for adoptive T cell therapy [145].

\section{EPIGENETIC MODULATION OF GENE EXPRESSION BY TQ}

TQ-mediated anticancer activity has also been shown to involve epigenetic suppression or activation of specific genes $[57,146,147]$. TQ-induced p73 has been shown to represses the expression of the anti-apoptotic epigenetic integrator known as ubiquitin-like-containing PHD and RING finger domains (UHRF1) and its partner DNA methyltransferase 1 (DNMT1) $[57,69]$. Since UHRF1-DNMT1-histone deacety- 
lase (HDAC) complex is very much involved in epigenetic regulation of gene expression, the effect of TQ on p73 and UHRF1 provide an epigenetic basis through which TQ can modulate the expressions of diverse pro- and anti-apoptotic proteins. Results from ex vivo studies using cell lines derived from T-cell acute lymphoblastic leukemia and breast cancer have brought to light the ability of TQ to attenuate the expression of epigenetic regulator UHRF1 and its partners DNMT1, HDAC1, and euchromatic histone-lysine N-methyltransferase 1 [146]. Since UHRF1 is involved in silencing several tumor suppressor genes and pro-apoptotic genes in many cancers, TQ-mediated decrease in UHRF1 levels leads to the de-repression and increased expression of several tumor suppressor genes and pro-apoptotic genes in TQ-treated cells (Fig. 2). This has been demonstrated in Jurkat cells in which $T Q$ activates the expression of several tumor suppressor genes (DLC1, PPARG, ST7, FOXO6, TET2, CYP1B1, SALL4, and DDIT3) as well as proapoptotic genes (RASL11B, RASD1, $G N G 3, B A D$, and $B I K)$ through such epigenetic mechanism [146].

In addition to the UHRF1-mediated mechanism, a direct role for TQ in physically interacting with DNMT1 and inhibiting its DNA-methylation activity has also been proposed [148]. TQ has also been shown to inhibit HDAC activity, possibly through direct interactions with HDACs [64]. In MCF7 breast cancer cells, TQ inhibits the deacetylation activity of HDAC and reactivates the expression of p21, Mapsins, and Bax, thereby ushering the cells into $\mathrm{G} 2 / \mathrm{M}$ cell cycle arrest. It has also been observed that the chemical structure of TQ can also contribute to epigenetic regulation of gene expression [147]. Thus, TQ can donate or accept a methyl group from DNA, thus playing a mediatory role in DNA-methylation and demethylation respectively.

\section{CONCLUDING REIMARKS AND PERSPECTIVES}

As presented here, detailed experimental analysis of the biological activities of TQ has clearly established it as a multi-target inhibitor that exerts its chemopreventive and anticancer activities by inhibiting multiple pathways involved in tumorigenesis, tumor progression, and metastasis. It should be stressed here that none of these pathways are mutually exclusive. Often, they are inter-connected and overlapping (Fig. 2). The cumulative effects lead to the potent inhibition of cancer cell growth and progression by TQ. As discussed above, TQ has been shown to inhibit the cellular machinery and molecular targets underlying almost all of the hallmarks of cancer. Thus, the ability of $\mathrm{TQ}$ to inhibit multiple signaling pathways involved in cancer growth and progression highly underscores its potential as an ideal candidate for adjuvant therapy. Of particular interest are the findings that $\mathrm{TQ}$ can overcome resistance to various chemotherapeutic drugs and potentiate their efficacies while reducing their innate cytotoxicity [140]. Such chemo-potentiating effects of TQ in different cancer cells have been observed with 5-fluorouracil in gastric cancer and colorectal cancer models [149,150]; Bortezomib in multiple myeloma cell line [102]; Cisplatin in colon carcinoma [131], ovarian carcinoma [151], esophageal carcinoma [152], and lung cancer [59]; Doxorubicin in leukemia [33], melanoma, cervix, and breast cancer cell lines [153]; Docetaxel in prostate cancer [86,87]; Gemcitabine in breast [117] and pancreatic cancer [84] models; Oxaliplatin in osteosarcoma [154], pancreatic [155], and ovarian cancer [156] models; Paclitaxel in triple negative breast cancers [157]; Tamoxifen in breast cancer $[67,158]$; Temozolomide in glioblastoma [159]; and Topotecan in colorectal cancer [160] and acute myelogenous leukemia cell lines [161]. In addition to these chemopotentiation and chemosensitization effect, $\mathrm{TQ}$ has also been observed to have a radiosensitization and radioprotection effects in many cancers, such as breast [75] and head and neck cancers [162]. Collectively, these studies point to the potential role of $\mathrm{TQ}$ as an adjuvant therapeutic agent for many cancers.

However, it should be noted that the efficacy of TQ alone or in combination therapies could be context-specific. For example, TQ treatment along with paclitaxel reduced the potency of paclitaxel as evidenced by an increase in $\mathrm{IC}_{50}$ values for paclitaxel in the combination regiment. TQ has been shown to antagonize the therapeutic efficacy of paclitaxel in breast cancer cell lines [163]. It is also of importance to note that although TQ-cisplatin combination treatment showed synergy in an in vitro oral squamous cell carcinoma model, it contrarily increased cytotoxicity to normal oral epithelial cells [54]. In a similar vein, a recent in vivo study, while emphasizing the potency of TQ in combination therapy with cisplatin in ovarian cancer xenograft tumor growth [151], gives cautions that the long-term treatment with $\mathrm{TQ}$ leads to an increase in the NF- $\mathrm{KB}$ activity and attenuation of its therapeutic efficacy [164]. The observed attenuation of the therapeutic activity of TQ has been attributed to "microenvironmental effects". This is further substantiated by the observations that TQ could synergize with the pro-oncogenic activity of lysophosphatidic acid, which is present in ovarian cancer tumor microenvironment [165]. Specifically, TQ has been demonstrated to augment lysophosphatidic acid-induced glycolytic shift in ovarian cancer cells. Thus, context-specific effects of TQ need to be considered in the development of TQ-based anticancer therapeutic strategy. Nevertheless, mounting evidence from the in vitro and in vivo studies collectively underscore and validate the role of TQ as a potent chemopreventive as well as therapeutic agent. Despite its well-established role as a multi-targeted chemopreventive agent, detailed human studies are still lacking. To date, there has been only one Phase 1 clinical trial with TQ [31]. While the results from the Phase I trial quite significantly established the safe dosage for administration, the anticancer effect of TQ at the administered tolerant dosage could not be successfully established. This has been pri- 
marily attributed to the physicochemical characteristics of TQ and its relatively poor bioavailability. However, with the development of the second generation TQ analogues [166,167] and novel nanoparticle-based delivery systems [168,169], it should be possible to embark on new human clinical trials and establish the role of TQ in effective therapeutic regimen for many cancers.

\section{ACKNOWLEDMENTS}

This research was supported by National Institutes of Health grant GM103639 and Stephenson Cancer Center, OUHSC, Oklahoma City, OK (to DN Dhanasekaran). Research reported in this publication was supported in part by the National Cancer Institute Cancer Center Support Grant P30CA225520 and Institutional Development Award (IDeA) from the National Institute of General Medical Sciences of the National Institutes of Health grant P20 GM103639 awarded to the University of Oklahoma Health Sciences Center. The content is solely the responsibility of the authors and does not necessarily represent the official views of the National Institutes of Health. The authors apologize to all the investigators, whose studies were not cited either due to oversight or space constraints.

\section{CONFLICTS OF INTEREST}

No potential conflicts of interest were disclosed.

\section{ORCID}

Rohini Gomathinayagam, https://orcid.org/0000-0001-7626-3403

Ji Hee Ha,

https://orcid.org/0000-0002-6281-1904

Muralidharan Jayaraman, https://orcid.org/0000-0003-3274-877X

Yong Sang Song, https://orcid.org/0000-0001-7115-4021

Ciro Isidoro, https://orcid.org/0000-0002-5494-3034

Danny N. Dhanasekaran, https://orcid.org/0000-0001-6350-8926

\section{REFERENCES}

1. Surh YJ. Cancer chemoprevention with dietary phytochemicals. Nat Rev Cancer 2003;3:768-80.

2. Wu X, Lippman SM. An intermittent approach for cancer chemoprevention. Nat Rev Cancer 2011;11:879-85.

3. Koh YC, Ho CT, Pan MH. Recent advances in cancer chemoprevention with phytochemicals. J Food Drug Anal 2020;28:14-37.

4. Liskova A, Stefanicka P, Samec M, Smejkal K, Zubor P, Bielik T, et al. Dietary phytochemicals as the potential protectors against carcinogenesis and their role in cancer chemoprevention. Clin Exp Med 2020;20:173-90.

5. Wattenberg LW. Chemoprevention of cancer. Cancer Res 1985;45:1-8.

6. Sporn MB. Approaches to prevention of epithelial cancer during the preneoplastic period. Cancer Res 1976;36(7 PT 2):2699702.

7. Kelloff GJ, Sigman CC, Johnson KM, Boone CW, Greenwald P, Crowell JA, et al. Perspectives on surrogate end points in the development of drugs that reduce the risk of cancer. Cancer Epidemiol Biomarkers Prev 2000;9:127-37.

8. Kelloff GJ. Perspectives on cancer chemoprevention research and drug development. Adv Cancer Res 2000;78:199-334.

9. Liu RH. Health benefits of fruit and vegetables are from additive and synergistic combinations of phytochemicals. Am J Clin Nutr 2003;78(3 Suppl):517S-20S.

10. Milner JA. Molecular targets for bioactive food components. J Nutr 2004;134:2492S-8S.

11. Han Y, Jo H, Cho JH, Dhanasekaran DN, Song YS. Resveratrol as a tumor-suppressive nutraceutical modulating tumor microenvironment and malignant behaviors of cancer. Int $\mathrm{J} \mathrm{Mol}$ Sci 2019;20:925.

12. Ali BH, Blunden G. Pharmacological and toxicological properties of Nigella sativa. Phytother Res 2003;17:299-305.

13. Ahmad A, Husain A, Mujeeb M, Khan SA, Najmi AK, Siddique NA, et al. A review on therapeutic potential of Nigella sativa: a miracle herb. Asian Pac J Trop Biomed 2013;3:337-52.

14. Darakhshan S, Bidmeshki Pour A, Hosseinzadeh Colagar A, Sisakhtnezhad $\mathrm{S}$. Thymoquinone and its therapeutic potentials. Pharmacol Res 2015;95-96:138-58.

15. Khader M, Eckl PM. Thymoquinone: an emerging natural drug with a wide range of medical applications. Iran J Basic Med Sci 2014;17:950-7.

16. Hanahan D, Weinberg RA. The hallmarks of cancer. Cell 2000;100:57-70.

17. Hanahan D, Weinberg RA. Hallmarks of cancer: the next generation. Cell 2011;144:646-74.

18. Sonnenschein C, Soto AM. The aging of the 2000 and 2011 Hallmarks of Cancer reviews: a critique. J Biosci 2013;38:65163.

19. Schneider-Stock R, Fakhoury IH, Zaki AM, El-Baba CO, GaliMuhtasib HU. Thymoquinone: fifty years of success in the battle against cancer models. Drug Discov Today 2014;19:18-30.

20. Leri M, Scuto M, Ontario ML, Calabrese V, Calabrese EJ, Bucciantini M, et al. Healthy effects of plant polyphenols: molecular mechanisms. Int J Mol Sci 2020;21:1250.

21. Negri A, Naponelli V, Rizzi F, Bettuzzi S. Molecular targets of epigallocatechin-gallate (EGCG): a special focus on signal transduction and cancer. Nutrients 2018;10:1936.

22. Vidoni C, Ferraresi A, Secomandi E, Vallino L, Dhanasekaran $\mathrm{DN}$, Isidoro $\mathrm{C}$. Epigenetic targeting of autophagy for cancer prevention and treatment by natural compounds [published online ahead of print May 2, 2019]. Semin Cancer Biol. doi: 
10.1016/j.semcancer.2019.04.006.

23. Goyal SN, Prajapati CP, Gore PR, Patil CR, Mahajan UB, Sharma $C$, et al. Therapeutic potential and pharmaceutical development of thymoquinone: a multitargeted molecule of natural origin. Front Pharmacol 2017;8:656.

24. Bolton JL, Trush MA, Penning TM, Dryhurst G, Monks TJ. Role of quinones in toxicology. Chem Res Toxicol 2000;13:135-60.

25. Mansour MA, Nagi MN, El-Khatib AS, Al-Bekairi AM. Effects of thymoquinone on antioxidant enzyme activities, lipid peroxidation and DT-diaphorase in different tissues of mice: a possible mechanism of action. Cell Biochem Funct 2002;20:14351.

26. Mahmoud YK, Abdelrazek HMA. Cancer: thymoquinone antioxidant/pro-oxidant effect as potential anticancer remedy. Biomed Pharmacother 2019;115:108783.

27. Nagi MN, Mansour MA. Protective effect of thymoquinone against doxorubicin-induced cardiotoxicity in rats: a possible mechanism of protection. Pharmacol Res 2000;41:283-9.

28. Krylova NG, Drobysh MS, Semenkova GN, Kulahava TA, Pinchuk SV, Shadyro OI. Cytotoxic and antiproliferative effects of thymoquinone on rat $\mathrm{C} 6$ glioma cells depend on oxidative stress. Mol Cell Biochem 2019;462:195-206.

29. Khalife KH, Lupidi G. Nonenzymatic reduction of thymoquinone in physiological conditions. Free Radic Res 2007;41:153-61.

30. Tekbas A, Huebner J, Settmacher U, Dahmen U. Plants and surgery: the protective effects of thymoquinone on hepatic injury-a systematic review of in vivo studies. Int $\mathrm{J}$ Mol Sci 2018;19:1085.

31. Asaduzzaman Khan M, Tania M, Fu S, Fu J. Thymoquinone, as an anticancer molecule: from basic research to clinical investigation. Oncotarget 2017;8:51907-19.

32. Ahmad A, Mishra RK, Vyawahare A, Kumar A, Rehman MU, Qamar W, et al. Thymoquinone (2-lsoprpyl-5-methyl-1, 4-benzoquinone) as a chemopreventive/anticancer agent: chemistry and biological effects. Saudi Pharm J 2019;27:111326.

33. Fatfat M, Fakhoury I, Habli Z, Mismar R, Gali-Muhtasib H. Thymoquinone enhances the anticancer activity of doxorubicin against adult T-cell leukemia in vitro and in vivo through ROSdependent mechanisms. Life Sci 2019;232:116628.

34. Zubair H, Khan HY, Sohail A, Azim S, Ullah MF, Ahmad A, et al. Redox cycling of endogenous copper by thymoquinone leads to ROS-mediated DNA breakage and consequent cell death: putative anticancer mechanism of antioxidants. Cell Death Dis 2013;4:e660.

35. Ashour AE, Abd-Allah AR, Korashy HM, Attia SM, Alzahrani $A Z$, Saquib $Q$, et al. Thymoquinone suppression of the human hepatocellular carcinoma cell growth involves inhibition of IL-8 expression, elevated levels of TRAIL receptors, oxidative stress and apoptosis. Mol Cell Biochem 2014;389:85-98.

36. Ahmad I, Muneer KM, Tamimi IA, Chang ME, Ata MO, Yusuf $\mathrm{N}$. Thymoquinone suppresses metastasis of melanoma cells by inhibition of NLRP3 inflammasome. Toxicol Appl Pharmacol 2013;270:70-6.
37. Park JE, Kim DH, Ha E, Choi SM, Choi JS, Chun KS, et al. Thymoquinone induces apoptosis of human epidermoid carcinoma A431 cells through ROS-mediated suppression of STAT3. Chem Biol Interact 2019;312:108799.

38. Woo CC, Hsu A, Kumar AP, Sethi G, Tan KH. Thymoquinone inhibits tumor growth and induces apoptosis in a breast cancer xenograft mouse model: the role of p38 MAPK and ROS. PLoS One 2013;8:e75356.

39. Liou YF, Chen PN, Chu SC, Kao SH, Chang YZ, Hsieh YS, et al. Thymoquinone suppresses the proliferation of renal cell carcinoma cells via reactive oxygen species-induced apoptosis and reduces cell stemness. Environ Toxicol 2019;34:1208-20.

40. Costa JG, Keser V, Jackson C, Saraiva N, Guerreiro Í, Almeida $\mathrm{N}$, et al. A multiple endpoint approach reveals potential in vitro anticancer properties of thymoquinone in human renal carcinoma cells. Food Chem Toxicol 2020;136:111076.

41. Taha MM, Sheikh BY, Salim LZ, Mohan S, Khan A, Kamalidehghan B, et al. Thymoquinone induces apoptosis and increase ROS in ovarian cancer cell line. Cell Mol Biol (Noisy-legrand) 2016;62:97-101.

42. Helmy SA, El-Mesery M, El-Karef A, Eissa LA, El Gayar AM. Thymoquinone upregulates TRAIL/TRAILR2 expression and attenuates hepatocellular carcinoma in vivo model. Life Sci 2019;233:116673.

43. Hussain AR, Ahmed M, Ahmed S, Manogaran P, Platanias LC, Alvi SN, et al. Thymoquinone suppresses growth and induces apoptosis via generation of reactive oxygen species in primary effusion lymphoma. Free Radic Biol Med 2011;50:978-87.

44. Koka PS, Mondal D, Schultz M, Abdel-Mageed AB, Agrawal KC. Studies on molecular mechanisms of growth inhibitory effects of thymoquinone against prostate cancer cells: role of reactive oxygen species. Exp Biol Med (Maywood) 2010;235:751-60.

45. Tang $H$, Hao Q, Rutherford SA, Low B, Zhao ZJ. Inactivation of $\mathrm{SRC}$ family tyrosine kinases by reactive oxygen species in vivo. J Biol Chem 2005;280:23918-25.

46. Richards LR, Jones P, Hughes J, Benghuzzi H, Tucci M. The physiological effect of conventional treatment with epigallocatechin-3-gallate, thymoquinone, and tannic acid on the LNCaP cell line. Biomed Sci Instrum 2006;42:357-62.

47. Gali-Muhtasib H, Ocker M, Kuester D, Krueger S, El-Hajj Z, Diestel A, et al. Thymoquinone reduces mouse colon tumor cell invasion and inhibits tumor growth in murine colon cancer models. J Cell Mol Med 2008;12:330-42.

48. Jrah-Harzallah H, Ben-Hadj-Khalifa S, Almawi WY, Maaloul A, Houas Z, Mahjoub T. Effect of thymoquinone on 1,2-dimethylhydrazine-induced oxidative stress during initiation and promotion of colon carcinogenesis. Eur J Cancer 2013;49:112735.

49. Sayed-Ahmed MM, Aleisa AM, Al-Rejaie SS, Al-Yahya AA, AlShabanah OA, Hafez MM, et al. Thymoquinone attenuates diethylnitrosamine induction of hepatic carcinogenesis through antioxidant signaling. Oxid Med Cell Longev 2010;3:254-61.

50. Harzallah HJ, Grayaa R, Kharoubi W, Maaloul A, Hammami M, Mahjoub T. Thymoquinone, the Nigella sativa bioactive 
compound, prevents circulatory oxidative stress caused by 1,2-dimethylhydrazine in erythrocyte during colon postinitiation carcinogenesis. Oxid Med Cell Longev 2012;2012:854065.

51. Woo CC, Kumar AP, Sethi G, Tan KH. Thymoquinone: potential cure for inflammatory disorders and cancer. Biochem Pharmacol 2012;83:443-51.

52. Alenzi FQ, El-Bolkiny Yel-S, Salem ML. Protective effects of Nigella sativa oil and thymoquinone against toxicity induced by the anticancer drug cyclophosphamide. Br J Biomed Sci 2010;67:20-8.

53. Farooqui Z, Shahid F, Khan AA, Khan F. Oral administration of Nigella sativa oil and thymoquinone attenuates long term cisplatin treatment induced toxicity and oxidative damage in rat kidney. Biomed Pharmacother 2017;96:912-23.

54. Alaufi OM, Noorwali A, Zahran F, Al-Abd AM, Al-Attas S. Cytotoxicity of thymoquinone alone or in combination with cisplatin (CDDP) against oral squamous cell carcinoma in vitro. Sci Rep 2017;7:13131.

55. al-Shabanah OA, Badary OA, Nagi MN, al-Gharably NM, alRikabi AC, al-Bekairi AM. Thymoquinone protects against doxorubicin-induced cardiotoxicity without compromising its antitumor activity. J Exp Clin Cancer Res 1998;17:193-8.

56. Ismail M, Al-Naqeep G, Chan KW. Nigella sativa thymoquinonerich fraction greatly improves plasma antioxidant capacity and expression of antioxidant genes in hypercholesterolemic rats. Free Radic Biol Med 2010;48:664-72.

57. Alhosin M, Abusnina A, Achour M, Sharif T, Muller C, Peluso J, et al. Induction of apoptosis by thymoquinone in lymphoblastic leukemia Jurkat cells is mediated by a p73-dependent pathway which targets the epigenetic integrator UHRF1. Biochem Pharmacol 2010;79:1251-60.

58. Wirries A, Breyer S, Quint K, Schobert R, Ocker M. Thymoquinone hydrazone derivatives cause cell cycle arrest in p53-competent colorectal cancer cells. Exp Ther Med 2010;1:369-75.

59. Jafri SH, Glass J, Shi R, Zhang S, Prince M, Kleiner-Hancock $H$. Thymoquinone and cisplatin as a therapeutic combination in lung cancer: in vitro and in vivo. J Exp Clin Cancer Res 2010;29:87.

60. Ke X, Zhao Y, Lu X, Wang Z, Liu Y, Ren M, et al. TQ inhibits hepatocellular carcinoma growth in vitro and in vivo via repression of Notch signaling. Oncotarget 2015;6:32610-21.

61. Kaseb AO, Chinnakannu K, Chen D, Sivanandam A, Tejwani $\mathrm{S}$, Menon $\mathrm{M}$, et al. Androgen receptor and E2F-1 targeted thymoquinone therapy for hormone-refractory prostate cancer. Cancer Res 2007;67:7782-8.

62. Acharya BR, Chatterjee A, Ganguli A, Bhattacharya $S$, Chakrabarti $G$. Thymoquinone inhibits microtubule polymerization by tubulin binding and causes mitotic arrest following apoptosis in A549 cells. Biochimie 2014;97:78-91.

63. Xu D, Ma Y, Zhao B, Li S, Zhang Y, Pan S, et al. Thymoquinone induces G2/M arrest, inactivates PI3K/Akt and nuclear factor$\kappa B$ pathways in human cholangiocarcinomas both in vitro and in vivo. Oncol Rep 2014;31:2063-70.
64. Parbin S, Shilpi A, Kar S, Pradhan N, Sengupta D, Deb M, et al. Insights into the molecular interactions of thymoquinone with histone deacetylase: evaluation of the therapeutic intervention potential against breast cancer. Mol Biosyst 2016;12:48-58.

65. Sutton KM, Greenshields AL, Hoskin DW. Thymoquinone, a bioactive component of black caraway seeds, causes $\mathrm{G} 1$ phase cell cycle arrest and apoptosis in triple-negative breast cancer cells with mutant p53. Nutr Cancer 2014;66:408-18.

66. Rajput S, Kumar BN, Dey KK, Pal I, Parekh A, Mandal M. Molecular targeting of Akt by thymoquinone promotes $\mathrm{G}(1)$ arrest through translation inhibition of cyclin D1 and induces apoptosis in breast cancer cells. Life Sci 2013;93:783-90.

67. Rajput S, Kumar BN, Sarkar S, Das S, Azab B, Santhekadur PK, et al. Targeted apoptotic effects of thymoquinone and tamoxifen on XIAP mediated Akt regulation in breast cancer. PLoS One 2013;8:e61342.

68. Shoieb AM, Elgayyar M, Dudrick PS, Bell JL, Tithof PK. In vitro inhibition of growth and induction of apoptosis in cancer cell lines by thymoquinone. Int J Oncol 2003;22:107-13.

69. Abusnina A, Alhosin M, Keravis T, Muller CD, Fuhrmann $G$, Bronner $C$, et al. Down-regulation of cyclic nucleotide phosphodiesterase PDE1A is the key event of p73 and UHRF1 deregulation in thymoquinone-induced acute lymphoblastic leukemia cell apoptosis. Cell Signal 2011;23:152-60.

70. Li F, Rajendran P, Sethi G. Thymoquinone inhibits proliferation, induces apoptosis and chemosensitizes human multiple myeloma cells through suppression of signal transducer and activator of transcription 3 activation pathway. $\mathrm{Br} \mathrm{J}$ Pharmacol 2010;161:541-54.

71. Gali-Muhtasib HU, Abou Kheir WG, Kheir LA, Darwiche N, Crooks PA. Molecular pathway for thymoquinone-induced cell-cycle arrest and apoptosis in neoplastic keratinocytes. Anticancer Drugs 2004;15:389-99.

72. Yang J, Kuang XR, Lv PT, Yan XX. Thymoquinone inhibits proliferation and invasion of human nonsmall-cell lung cancer cells via ERK pathway. Tumour Biol 2015;36:259-69.

73. Kundu J, Choi BY, Jeong CH, Kundu JK, Chun KS. Thymoquinone induces apoptosis in human colon cancer HCT116 cells through inactivation of STAT3 by blocking JAK2and Src-mediated phosphorylation of EGF receptor tyrosine kinase. Oncol Rep 2014;32:821-8.

74. Barkat MA, Harshita, Ahmad J, Khan MA, Beg S, Ahmad FJ. Insights into the targeting potential of thymoquinone for therapeutic intervention against triple-negative breast cancer. Curr Drug Targets 2018;19:70-80.

75. Velho-Pereira R, Kumar A, Pandey BN, Jagtap AG, Mishra KP. Radiosensitization in human breast carcinoma cells by thymoquinone: role of cell cycle and apoptosis. Cell Biol Int 2011;35:1025-9.

76. Paramasivam A, Raghunandhakumar S, Priyadharsini $\mathrm{JV}$, Jayaraman G. In vitro anti-neuroblastoma activity of thymoquinone against Neuro-2a cells via cell-cycle arrest. Asian Pac J Cancer Prev 2015;16:8313-9.

77. Arafa el-SA, Zhu Q, Shah ZI, Wani G, Barakat BM, Racoma I, et 
al. Thymoquinone up-regulates PTEN expression and induces apoptosis in doxorubicin-resistant human breast cancer cells. Mutat Res 2011;706:28-35.

78. Gali-Muhtasib H, Diab-Assaf M, Boltze C, Al-Hmaira J, Hartig $\mathrm{R}$, Roessner $\mathrm{A}$, et al. Thymoquinone extracted from black seed triggers apoptotic cell death in human colorectal cancer cells via a p53-dependent mechanism. Int J Oncol 2004;25:857-66.

79. Badr G, Mohany M, Abu-Tarboush F. Thymoquinone decreases F-actin polymerization and the proliferation of human multiple myeloma cells by suppressing STAT3 phosphorylation and Bcl2/ Bcl-XL expression. Lipids Health Dis 2011;10:236.

80. Lee SR, Mun JY, Jeong MS, Lee HH, Roh YG, Kim WT, et al. Thymoquinone-induced tristetraprolin inhibits tumor growth and metastasis through destabilization of MUC4 mRNA. Int J Mol Sci 2019;20:2614.

81. Lai WS, Carballo E, Thorn JM, Kennington EA, Blackshear PJ. Interactions of $\mathrm{CCCH}$ zinc finger proteins with mRNA. Binding of tristetraprolin-related zinc finger proteins to Au-rich elements and destabilization of mRNA. J Biol Chem 2000;275:17827-37.

82. Park JM, Lee TH, Kang TH. Roles of tristetraprolin in tumorigenesis. Int J Mol Sci 2018;19:3384.

83. Kabil N, Bayraktar R, Kahraman N, Mokhlis HA, Calin GA, Lopez-Berestein G, et al. Thymoquinone inhibits cell proliferation, migration, and invasion by regulating the elongation factor 2 kinase (eEF-2K) signaling axis in triple-negative breast cancer. Breast Cancer Res Treat 2018;171:593-605.

84. Mu GG, Zhang LL, Li HY, Liao Y, Yu HG. Thymoquinone pretreatment overcomes the insensitivity and potentiates the antitumor effect of gemcitabine through abrogation of Notch1, $\mathrm{PI} 3 \mathrm{~K} / \mathrm{Akt} / \mathrm{mTOR}$ regulated signaling pathways in pancreatic cancer. Dig Dis Sci 2015;60:1067-80.

85. Ma J, Hu X, Li J, Wu D, Lan Q, Wang Q, et al. Enhancing conventional chemotherapy drug cisplatin-induced anti-tumor effects on human gastric cancer cells both in vitro and in vivo by Thymoquinone targeting PTEN gene. Oncotarget 2017;8:8592639.

86. Dirican A, Atmaca H, Bozkurt E, Erten C, Karaca B, Uslu R. Novel combination of docetaxel and thymoquinone induces synergistic cytotoxicity and apoptosis in DU-145 human prostate cancer cells by modulating PI3K-AKT pathway. Clin TransI Oncol 2015;17:145-51.

87. Singh SK, Apata T, Gordetsky JB, Singh R. Docetaxel combined with thymoquinone induces apoptosis in prostate cancer cells via inhibition of the PI3K/AKT signaling pathway. Cancers (Basel) 2019;11:1390.

88. Dera A, Rajagopalan P. Thymoquinone attenuates phosphorylation of AKT to inhibit kidney cancer cell proliferation. J Food Biochem 2019;43:e12793.

89. Das S, Dey KK, Dey G, Pal I, Majumder A, MaitiChoudhury S, et al. Antineoplastic and apoptotic potential of traditional medicines thymoquinone and diosgenin in squamous cell carcinoma. PLoS One 2012;7:e46641.

90. Liou YF, Hsieh YS, Hung TW, Chen PN, Chang YZ, Kao SH, et al. Thymoquinone inhibits metastasis of renal cell carcinoma cell 786-O-SI3 associating with downregulation of MMP-2 and $\mathrm{u}-\mathrm{PA}$ and suppression of PI3K/Src signaling. Int $\mathrm{J}$ Med Sci 2019;16:686-95.

91. Feng LM, Wang XF, Huang QX. Thymoquinone induces cytotoxicity and reprogramming of EMT in gastric cancer cells by targeting PI3K/Akt/mTOR pathway. J Biosci 2017;42:547-54.

92. Woo CC, Loo SY, Gee V, Yap CW, Sethi G, Kumar AP, et al. Anticancer activity of thymoquinone in breast cancer cells: possible involvement of PPAR- $\gamma$ pathway. Biochem Pharmacol 2011;82:464-75.

93. Chen $\mathrm{Y}$, Wang B, Zhao $\mathrm{H}$. Thymoquinone reduces spinal cord injury by inhibiting inflammatory response, oxidative stress and apoptosis via PPAR- $\gamma$ and PI3K/Akt pathways. Exp Ther Med 2018;15:4987-94.

94. Badr G, Lefevre EA, Mohany M. Thymoquinone inhibits the CXCL12-induced chemotaxis of multiple myeloma cells and increases their susceptibility to Fas-mediated apoptosis. PLoS One 2011;6:e23741.

95. Yi T, Cho SG, Yi Z, Pang X, Rodriguez M, Wang Y, et al. Thymoquinone inhibits tumor angiogenesis and tumor growth through suppressing AKT and extracellular signal-regulated kinase signaling pathways. Mol Cancer Ther 2008;7:1789-96.

96. Yu SM, Kim SJ. Thymoquinone-induced reactive oxygen species causes apoptosis of chondrocytes via PI3K/Akt and p38kinase pathway. Exp Biol Med (Maywood) 2013;238:811-20.

97. Motaghed M, Al-Hassan FM, Hamid SS. Thymoquinone regulates gene expression levels in the estrogen metabolic and interferon pathways in MCF7 breast cancer cells. Int J Mol Med 2014;33:8-16.

98. El-Najjar N, Chatila M, Moukadem H, Vuorela H, Ocker M, Gandesiri M, et al. Reactive oxygen species mediate thymoquinone-induced apoptosis and activate ERK and JNK signaling. Apoptosis 2010;15:183-95.

99. Torres MP, Ponnusamy MP, Chakraborty S, Smith LM, Das $S$, Arafat HA, et al. Effects of thymoquinone in the expression of mucin 4 in pancreatic cancer cells: implications for the development of novel cancer therapies. Mol Cancer Ther 2010;9:1419-31.

100. Chehl N, Chipitsyna G, Gong Q, Yeo CJ, Arafat HA. Antiinflammatory effects of the Nigella sativa seed extract, thymoquinone, in pancreatic cancer cells. HPB (Oxford) 2009;11:373-81.

101. Sethi G, Ahn KS, Aggarwal BB. Targeting nuclear factor-kappa $B$ activation pathway by thymoquinone: role in suppression of antiapoptotic gene products and enhancement of apoptosis. Mol Cancer Res 2008;6:1059-70.

102. Siveen KS, Mustafa N, Li F, Kannaiyan R, Ahn KS, Kumar AP, et al. Thymoquinone overcomes chemoresistance and enhances the anticancer effects of bortezomib through abrogation of NF$\kappa \mathrm{B}$ regulated gene products in multiple myeloma xenograft mouse model. Oncotarget 2014;5:634-48.

103. Relles D, Chipitsyna GI, Gong Q, Yeo CJ, Arafat HA. Thymoquinone promotes pancreatic cancer cell death and reduction of tumor size through combined inhibition of histone 
deacetylation and induction of histone acetylation. Adv Prev Med 2016;2016:1407840.

104. Paramasivam A, Sambantham S, Shabnam J, Raghunandhakumar S, Anandan B, Rajiv R, et al. Anti-cancer effects of thymoquinone in mouse neuroblastoma (Neuro-2a) cells through caspase-3 activation with down-regulation of XIAP. Toxicol Lett 2012;213:151-9.

105. El-Mahdy MA, Zhu Q, Wang QE, Wani G, Wani AA. Thymoquinone induces apoptosis through activation of caspase-8 and mitochondrial events in p53-null myeloblastic leukemia HL-60 cells. Int J Cancer 2005;117:409-17.

106. Rooney S, Ryan MF. Modes of action of alpha-hederin and thymoquinone, active constituents of Nigella sativa, against HEp-2 cancer cells. Anticancer Res 2005;25(6B):4255-9.

107. Roepke M, Diestel A, Bajbouj K, Walluscheck D, Schonfeld P, Roessner A, et al. Lack of p53 augments thymoquinone-induced apoptosis and caspase activation in human osteosarcoma cells. Cancer Biol Ther 2007;6:160-9.

108. Zhang M, Du H, Huang Z, Zhang P, Yue Y, Wang W, et al. Thymoquinone induces apoptosis in bladder cancer cell via endoplasmic reticulum stress-dependent mitochondrial pathway. Chem Biol Interact 2018;292:65-75.

109. Dastjerdi MN, Mehdiabady EM, Iranpour FG, Bahramian $\mathrm{H}$. Effect of thymoquinone on P53 gene expression and consequence apoptosis in breast cancer cell line. Int J Prev Med 2016;7:66.

110. Gali-Muhtasib H, Kuester D, Mawrin C, Bajbouj K, Diestel A, Ocker $\mathrm{M}$, et al. Thymoquinone triggers inactivation of the stress response pathway sensor CHEK1 and contributes to apoptosis in colorectal cancer cells. Cancer Res 2008;68:5609-18.

111. Pflaum J, Schlosser S, Müller M. p53 family and cellular stress responses in cancer. Front Oncol 2014;4:285.

112. Yoon MK, Ha JH, Lee MS, Chi SW. Structure and apoptotic function of p73. BMB Rep 2015;48:81-90.

113. Apel A, Zentgraf H, Büchler MW, Herr I. Autophagy-a doubleedged sword in oncology. Int J Cancer 2009;125:991-5.

114. White E, DiPaola RS. The double-edged sword of autophagy modulation in cancer. Clin Cancer Res 2009;15:5308-16.

115. Chu SC, Hsieh YS, Yu CC, Lai YY, Chen PN. Thymoquinone induces cell death in human squamous carcinoma cells via caspase activation-dependent apoptosis and LC3-II activationdependent autophagy. PLoS One 2014;9:e101579.

116. Zhang Y, Fan Y, Huang S, Wang G, Han R, Lei F, et al. Thymoquinone inhibits the metastasis of renal cell cancer cells by inducing autophagy via AMPK/mTOR signaling pathway. Cancer Sci 2018;109:3865-73.

117. Bashmail HA, Alamoudi AA, Noorwali A, Hegazy GA, AJabnoor $\mathrm{G}$, Choudhry $\mathrm{H}$, et al. Thymoquinone synergizes gemcitabine anti-breast cancer activity via modulating its apoptotic and autophagic activities. Sci Rep 2018;8:11674.

118. Chen MC, Lee NH, Hsu HH, Ho TJ, Tu CC, Hsieh DJ, et al. Thymoquinone induces caspase-independent, autophagic cell death in CPT-11-resistant lovo colon cancer via mitochondrial dysfunction and activation of JNK and p38. J Agric Food Chem
2015;63:1540-6.

119. Pazhouhi M, Sariri R, Rabzia A, Khazaei M. Thymoquinone synergistically potentiates temozolomide cytotoxicity through the inhibition of autophagy in U87MG cell line. Iran J Basic Med Sci 2016;19:890-98.

120. Racoma IO, Meisen WH, Wang QE, Kaur B, Wani AA. Thymoquinone inhibits autophagy and induces cathepsinmediated, caspase-independent cell death in glioblastoma cells. PLoS One 2013;8:e72882.

121. Khan MA, Tania M, Wei C, Mei Z, Fu S, Cheng J, et al. Thymoquinone inhibits cancer metastasis by downregulating TWIST1 expression to reduce epithelial to mesenchymal transition. Oncotarget 2015;6:19580-91.

122. Iskender B, Izgi K, Hizar E, Jauch J, Arslanhan A, Yuksek EH, et al. Inhibition of epithelial-mesenchymal transition in bladder cancer cells via modulation of mTOR signalling. Tumour Biol 2016;37:8281-91.

123. Zhang M, Du H, Wang L, Yue Y, Zhang P, Huang Z, et al. Thymoquinone suppresses invasion and metastasis in bladder cancer cells by reversing EMT through the Wnt/ $\beta$-catenin signaling pathway. Chem Biol Interact 2020;320:109022.

124. Li J, Khan MA, Wei C, Cheng J, Chen H, Yang L, et al. Thymoquinone inhibits the migration and invasive characteristics of cervical cancer cells $\mathrm{SiHa}$ and CaSki in vitro by targeting epithelial to mesenchymal transition associated transcription factors Twist1 and Zeb1. Molecules 2017;22:2105.

125. Kou B, Liu W, Zhao W, Duan P, Yang Y, Yi Q, et al. Thymoquinone inhibits epithelial-mesenchymal transition in prostate cancer cells by negatively regulating the TGF- $\beta /$ Smad2/3 signaling pathway. Oncol Rep 2017;38:3592-8.

126. Kolli-Bouhafs K, Boukhari A, Abusnina A, Velot E, Gies JP, Lugnier $C$, et al. Thymoquinone reduces migration and invasion of human glioblastoma cells associated with FAK, MMP-2 and MMP-9 down-regulation. Invest New Drugs 2012;30:2121-31.

127. Rajput S, Kumar BN, Banik P, Parida S, Mandal M. Thymoquinone restores radiation-induced TGF- $\beta$ expression and abrogates EMT in chemoradiotherapy of breast cancer cells. J Cell Physiol 2015;230:620-9.

128. Shanmugam MK, Ahn KS, Hsu A, Woo CC, Yuan Y, Tan KHB, et al. Thymoquinone inhibits bone metastasis of breast cancer cells through abrogation of the CXCR4 signaling axis. Front Pharmacol 2018;9:1294.

129. Rashid M, Sanjarin F, Sabouni F. Thymoquinone effects on cell viability, apoptosis and VEGF-A gene expression level in AGS(CRL-1739) cell line. Anticancer Agents Med Chem 2019;19:820-6.

130. Peng L, Liu A, Shen Y, Xu HZ, Yang SZ, Ying XZ, et al. Antitumor and anti-angiogenesis effects of thymoquinone on osteosarcoma through the NF-kB pathway. Oncol Rep 2013;29:571-8.

131. Zhang L, Bai Y, Yang Y. Thymoquinone chemosensitizes colon cancer cells through inhibition of NF-kB. Oncol Lett 2016;12:2840-5.

132. Salem ML. Immunomodulatory and therapeutic properties of the 
Nigella sativa L. seed. Int Immunopharmacol 2005;5:1749-70.

133. Majdalawieh AF, Fayyad MW. Immunomodulatory and antiinflammatory action of Nigella sativa and thymoquinone: a comprehensive review. Int Immunopharmacol 2015;28:295-304.

134. Houghton PJ, Zarka R, de las Heras B, Hoult JR. Fixed oil of Nigella sativa and derived thymoquinone inhibit eicosanoid generation in leukocytes and membrane lipid peroxidation. Planta Med 1995;61:33-6.

135. Mansour M, Tornhamre S. Inhibition of 5-lipoxygenase and leukotriene $\mathrm{C} 4$ synthase in human blood cells by thymoquinone. J Enzyme Inhib Med Chem 2004;19:431-6.

136. Hossen MJ, Yang WS, Kim D, Aravinthan A, Kim JH, Cho JY. Thymoquinone: an IRAK1 inhibitor with in vivo and in vitro antiinflammatory activities. Sci Rep 2017;7:42995.

137. Korbecki J, Baranowska-Bosiacka I, Gutowska I, Chlubek D. The effect of reactive oxygen species on the synthesis of prostanoids from arachidonic acid. J Physiol Pharmacol 2013;64:409-21.

138. Shaterzadeh-Yazdi H, Noorbakhsh MF, Hayati F, Samarghandian S, Farkhondeh T. Immunomodulatory and antiinflammatory effects of thymoquinone. Cardiovasc Hematol Disord Drug Targets 2018;18:52-60.

139. Gholamnezhad Z, Rafatpanah H, Sadeghnia HR, Boskabady $\mathrm{MH}$. Immunomodulatory and cytotoxic effects of Nigella sativa and thymoquinone on rat splenocytes. Food Chem Toxicol 2015;86:72-80.

140. Mostofa AGM, Hossain MK, Basak D, Bin Sayeed MS. Thymoquinone as a potential adjuvant therapy for cancer treatment: evidence from preclinical studies. Front Pharmacol 2017;8:295.

141. Xuan NT, Shumilina E, Qadri SM, Götz F, Lang F. Effect of thymoquinone on mouse dendritic cells. Cell Physiol Biochem 2010;25:307-14.

142. Salim LZ, Othman R, Abdulla MA, Al-Jashamy K, Ali HM, Hassandarvish $P$, et al. Thymoquinone inhibits murine leukemia WEHI-3 cells in vivo and in vitro. PLoS One 2014;9:e115340.

143. Badr G, Alwasel S, Ebaid H, Mohany M, Alhazza I. Perinatal supplementation with thymoquinone improves diabetic complications and T cell immune responses in rat offspring. Cell Immunol 2011;267:133-40.

144. Mohany M, El-Feki M, Refaat I, Garraud O, Badr G. Thymoquinone ameliorates the immunological and histological changes induced by exposure to imidacloprid insecticide. J Toxicol Sci 2012;37:1-11.

145. Salem ML, Alenzi FQ, Attia WY. Thymoquinone, the active ingredient of Nigella sativa seeds, enhances survival and activity of antigen-specific CD8-positive T cells in vitro. Br J Biomed Sci 2011;68:131-7.

146. Qadi SA, Hassan MA, Sheikh RA, Baothman OA, Zamzami MA, Choudhry $\mathrm{H}$, et al. Thymoquinone-induced reactivation of tumor suppressor genes in cancer cells involves epigenetic mechanisms. Epigenet Insights 2019;12:2516865719839011.

147. Khan MA, Tania M, Fu J. Epigenetic role of thymoquinone: impact on cellular mechanism and cancer therapeutics. Drug
Discov Today 2019;24:2315-22.

148. Pang J, Shen N, Yan F, Zhao N, Dou L, Wu LC, et al. Thymoquinone exerts potent growth-suppressive activity on leukemia through DNA hypermethylation reversal in leukemia cells. Oncotarget 2017;8:34453-67.

149. Norwood AA, Tucci M, Benghuzzi H. A comparison of 5-fluorouracil and natural chemotherapeutic agents, EGCG and thymoquinone, delivered by sustained drug delivery on colon cancer cells. Biomed Sci Instrum 2007;43:272-7.

150. Lei X, Lv X, Liu M, Yang Z, Ji M, Guo X, et al. Thymoquinone inhibits growth and augments 5-fluorouracil-induced apoptosis in gastric cancer cells both in vitro and in vivo. Biochem Biophys Res Commun 2012;417:864-8.

151. Wilson AJ, Saskowski J, Barham W, Yull F, Khabele D. Thymoquinone enhances cisplatin-response through direct tumor effects in a syngeneic mouse model of ovarian cancer. $J$ Ovarian Res 2015;8:46.

152. Hu X, Ma J, Vikash V, Li J, Wu D, Liu Y, et al. Thymoquinone augments cisplatin-induced apoptosis on esophageal carcinoma through mitigating the activation of JAK2/STAT3 pathway. Dig Dis Sci 2018;63:126-34.

153. Effenberger-Neidnicht K, Schobert R. Combinatorial effects of thymoquinone on the anti-cancer activity of doxorubicin. Cancer Chemother Pharmacol 2011;67:867-74.

154. Sarman H, Bayram R, Benek SB. Anticancer drugs with chemotherapeutic interactions with thymoquinone in osteosarcoma cells. Eur Rev Med Pharmacol Sci 2016;20:126370.

155. Banerjee S, Kaseb AO, Wang Z, Kong D, Mohammad M, Padhye $\mathrm{S}$, et al. Antitumor activity of gemcitabine and oxaliplatin is augmented by thymoquinone in pancreatic cancer. Cancer Res 2009;69:5575-83.

156. Nessa MU, Beale P, Chan C, Yu JQ, Huq F. Synergism from combinations of cisplatin and oxaliplatin with quercetin and thymoquinone in human ovarian tumour models. Anticancer Res 2011;31:3789-97.

157. Şakalar Ç, İzgi K, İskender B, Sezen S, Aksu H, Çakır M, et al. The combination of thymoquinone and paclitaxel shows antitumor activity through the interplay with apoptosis network in triple-negative breast cancer. Tumour Biol 2016;37:4467-77.

158. Ganji-Harsini S, Khazaei M, Rashidi Z, Ghanbari A. Thymoquinone could increase the efficacy of tamoxifen induced apoptosis in human breast cancer cells: an in vitro study. Cell $\mathrm{J}$ 2016;18:245-54.

159. Pazhouhi M, Sariri R, Khazaei MR, Moradi MT, Khazaei M. Synergistic effect of temozolomide and thymoquinone on human glioblastoma multiforme cell line (U87MG). J Cancer Res Ther 2018;14:1023-8.

160. Khalife R, Hodroj MH, Fakhoury R, Rizk S. Thymoquinone from Nigella sativa seeds promotes the antitumor activity of noncytotoxic doses of topotecan in human colorectal cancer cells in vitro. Planta Med 2016;82:312-21.

161. Khalife R, El-Hayek S, Tarras O, Hodroj MH, Rizk S. Antiproliferative and proapoptotic effects of topotecan in 
combination with thymoquinone on acute myelogenous leukemia. Clin Lymphoma Myeloma Leuk 2014;14 Suppl:S4655.

162. Kotowski U, Heiduschka G, Kadletz L, Fahim T, Seemann R, Schmid $R$, et al. Effect of thymoquinone on head and neck squamous cell carcinoma cells in vitro: synergism with radiation. Oncol Lett 2017;14:1147-51.

163. Bashmail HA, Alamoudi AA, Noorwali A, Hegazy GA, Ajabnoor GM, Al-Abd AM. Thymoquinone enhances paclitaxel anti-breast cancer activity via inhibiting tumor-associated stem cells despite apparent mathematical antagonism. Molecules 2020;25:426.

164. Wilson AJ, Saskowski J, Barham W, Khabele D, Yull F. Microenvironmental effects limit efficacy of thymoquinone treatment in a mouse model of ovarian cancer. Mol Cancer 2015;14:192.

165. Ha JH, Jayaraman M, Radhakrishnan R, Gomathinayagam R, Yan M, Song YS, et al. Differential effects of thymoquinone on lysophosphatidic acid-induced oncogenic pathways in ovarian cancer cells. J Tradit Complement Med 2020;10:207-16.

166. Severina II, Severin FF, Korshunova GA, Sumbatyan NV, llyasova TM, Simonyan RA, et al. In search of novel highly active mitochondria-targeted antioxidants: thymoquinone and its cationic derivatives. FEBS Lett 2013;587:2018-24.

167. Fröhlich T, Reiter C, Saeed MEM, Hutterer C, Hahn F, Leidenberger $\mathrm{M}$, et al. Synthesis of thymoquinone-artemisinin hybrids: new potent antileukemia, antiviral, and antimalarial agents. ACS Med Chem Lett 2017;9:534-9.

168. Goel S, Mishra P. Thymoquinone loaded mesoporous silica nanoparticles retard cell invasion and enhance in vitro cytotoxicity due to ROS mediated apoptosis in HeLa and MCF7 cell lines. Mater Sci Eng C Mater Biol Appl 2019;104:109881.

169. El-Far AH, Al Jaouni SK, Li W, Mousa SA. Protective roles of thymoquinone nanoformulations: potential nanonutraceuticals in human diseases. Nutrients 2018;10:1369. 